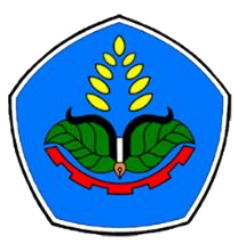

AGROPROSS

National Conference

Proceedings of Agriculture

\section{Proceedings: \\ Peran Teaching Factory Di Perguruan Tinggi Vokasi Dalam Mendukung Ketahanan Pangan Pada Era New Normal}

Tempat : Politeknik Negeri Jember

Tanggal : 8-9 Juli 2020

\section{Publisher:}

Agropross, National Conference Proceedings of Agriculture ISBN : 978-623-94036-6-9

DOI : 10.25047 /agropross.2020.35

\title{
Pengaruh Curah Hujan dan Pemupukan terhadap Rendemen Tebu di PG Asembagus Situbondo
}

\author{
Author(s): Dian Hartatie ${ }^{(1)}$, Irma Harlianingtyas ${ }^{(1)^{*}}$, Supriyadi ${ }^{(1)}$ \\ (1) Program Studi Produksi Tanaman Perkebunan, Jurusan Produksi Pertanian, Politeknik Negeri Jember \\ * Corresponding author: irma@polije.ac.id
}

\begin{abstract}
Rainfall is one of the climate elements which is very important in sugarcane cultivation. So that rainfall becomes an important factor in determining the yield of sugarcane produced. One of the important factors that can affect the yield of sugarcane is fertilizer dosage. Nutrient content given to sugarcane also affects the sugar content produced by sugarcane. Sugarcane yield is the content of sugar in sugarcane stems expressed in percent. PG Asembagoes is one of the sugar factories in East Java owned by PTPN XI. This study aims to determine the effect of rainfall and fertilization on sugarcane yield in PG Asembagus Situbondo. The research method uses regression analysis with rainfall and fertilization as independent variables and sugarcane yield as the dependent variable. The results showed that simultaneous or simultaneous rainfall and fertilization had a significant effect on sugarcane yield in PG. Asembagus with its regression equation is $y=4.373+$ 0.0167 Rainfall +0.0022 Fertilization and the magnitude of the coefficient of determination is $75.08 \%$. Regression model. This is expected to provide recommendations and policies for improving production at PG Asembagus Situbondo.
\end{abstract} Keyword:

Yield;

Sugar cane,

Rainfall;

Fertilization;

Regression;

\section{Kata Kunci: \\ Rendemen; \\ Tebu; \\ Curah hujan; \\ Pemupukan; \\ Regresi;}

\begin{abstract}
ABSTRAK
Iklim merupakan salah satu penentu keberhasilan swasembda gula di Indonesia. Curah hujan merupakan salah satu unsur iklim yang sangat penting dalam budidaya tebu. Sehingga curah hujan menjadi faktor penting dalam memenentukan rendemen tebu yang dihasilkan. Salah satu faktor penting yang dapat mempengaruhi rendemen tebu adalah dosis pemupukan.Unsur hara yang diberikan pada tanaman tebu turut mempengaruhi kadar gula yang dihasilkan tanman tebu. Rendemen tebu adalah kadar kandungan gula didalam batang tebu yang dinyatakan dengan persen. PG Asembagoes adalah salah satu pabrik gula yang ada di Jawa Timur milik PTPN XI. Penelitian ini bertujuan untuk mengetahui pengaruh curah hujan dan pemupukan terhadap rendemen tebu di PG Asembagus Situbondo. Metode penelitian menggunakan analisi regresi dengan curah hujan dan pemupukan sebagai veriabel bebas dan rendemen tebu sebagai variabel terikat. Hasil penelitian menunjukkan bahwa curah hujan dan pemupukan secara simultan atau bersamaan berpengaruh signifikan terhadap rendemen tebu di PG. Asembagus dengan persamaan regresinya adalah $y=4,373+0,0167$ Curah Hujan+0,0022Pemupukan dan besarnya koefisien determinasi 75,08\%. Model regresi. ini diharapkan mampu memberikan rekomendasi serta kebijakan guna perbaikan produksi di PG Asembagus Situbondo.
\end{abstract}




\section{PENDAHULUAN}

Gula menjadi salah satu kebutuhan pokok yang sangat penting bagi masyarakat dan industri yang pada saat ini masih terus menjadi permasalahan karena industri gula dalam negeri belum mampu memenuhi permintaanmasyarakat terhadap gula dan sementara kebutuhan gula dalam negeri dari tahun ke tahun terus mengalami peningkatan. Peningkatan permintaan gula dalam negeri harus diimbangi dengan adanya peningkatan produksi tebu. Produksi tebu akan meningkat sejalan dengan meningkatnya nilai rendemen tebu. Penurunan rendemen tebu dapat disebabkan oleh beberapa hal seperti proses budidaya, kualitas bibit yang rendah, iklim yang terjadi serta pasokan unsur hara ke dalam tanah.

Faktor iklim terutama curah hujan turut menentukan pertumbuhan dan produksi tebu, yang nantinya akan berpengaruh terhadap kadar gula atau nira tebu, serta mempengaruhi besaran produksi gula. Kejadian anomali iklim di Indonesia telah terbukti mempengaruhi produksi pertanian. Untuk itu karakteristik perubahan anomali iklim perlu dikuantifikasi besaran (magnitude) agar dampak anomali iklim dapat diantisipasi lebih dini dan diminimalkan resikonya (Estiningtyas et al., 2008). Perubahan iklim yang terjadi menyebabkan pola curah hujan menjadi tidak menentu dan sangat berpengaruh terhadap musim tanam.

Dimasa pertumbuhannya, tanaman tebu memerlukan perbedaan nyata antara musim hujan dan kemarau. Pada umumnya tanaman tebu membutuhkan curah hujan tahunan antara 1.000-1.300 mm/tahun. Selama masa vegetatifnya tebu membutuhkan banyak air, sedangkan pada akhir masa vegetatif atau menjelang tebu masak untuk dipanen maka tebu membutuhkan keadaan kering atau tidak ada hujan yang menyebabkan terhentinya pertumbuhan tebu dan memulai proses penimbunan sukrosa dalam batang tebu.
Apabila curah hujan cukup tinggi maka kesempatan tanaman tebu untuk matang terus tertunda sehingga menyebabkan kadar gula atau nira tebu turun dan berakibat terhadap produksi gula rendah kerena rendemennya kecil.

Selain faktor curah hujan, faktor utama yang mempengaruhi produksi tebu yaitu pemupukan. (Rosdianingsih, 2013) menyatakan bahwa pemupukan harus memperhatikan kebutuhan tanaman dan ketersediaan unsur hara dalam tanah yang dibutuhkan oleh tanaman tebu, sehingga dosis pupuk yang diberikan setiap lokasi berbeda. Pada umumnya tanaman tebu membutuhkan 3 jenis pupuk yang berbeda yaitu ZA 8-9 Ku/Ha, SP36 $2 \mathrm{Ku} / \mathrm{Ha}$, dan $\mathrm{KCl} 2 \mathrm{Ku} / \mathrm{Ha}$. Permasalahan yang dialami saat ini beberapa petani tebu mengaplikasikan pupuk tidak seperti dosis anjuran , sehingga tanaman tebu hasilnya tidak maksimal.

Rendemen adalah kadar gula yang terkandung dalam tebu (Supriadi, 1992). Peningkatan nilai rendemen dapat dilakukan, salah satunya melalui efisiensi pabrik gula. Untuk itu, diperlukan upaya nyata untuk merevitalisasi pabrik gula yang ada di Indonesia. Pabrik gula di Indonesia umumnya sudah berusia ratusan tahun karena sudah beroperasi sejak jaman Belanda di Indonesia. Selain itu, petani butuh ketersediaan benih dan pupuk yang berkualitas baik.

Selaras dengan hasil penelitian (Harlianingtyas et al., 2018) bahwa curah hujan dan pemupukan berpengaruh terhadap produktivitas tebu maka melaksanakan penelitian bagaimana pengaruh curah hujan dan pemupukan terhadap rendemen tebu di PG Asembagus Situbondo.

\section{BAHAN DAN METODE Sumber Data}

Sumber data yang digunakan dalam penelitian ini adalah data sekunder yang diambil di PG Asembagus Situbondo, 
yakni meliputi data pemupukan, curah hujan, dan rendemen tahun 2008 hingga 2018.

\section{Analisa Data}

Metode analisis data menggunakan analisis regresi berganda. Analisis regresi adalah suatu metode statistika untuk memprekdiksi nilai dari satu atau lebih variabel respon (depentdent variable) dari beberapa variabel prediktor (independent variable). Jika x1, x2, . ., $\mathrm{xp}$ adalah variabel prediktor sebanyak $p$ yang mempunyai hubungan dengan sebuah varibel respon $\mathrm{Y}$, maka secara umum model regresi liniar dengan satu variabel respon adalah

$Y=\beta_{0}+\beta_{1} X+\beta_{2} X .($ Sugiyono, 2017)

Variabel yang digunakan dalam penelitian ini terbagi menjadi dua, yaitu variabel prediktor dan variabel respon.
Variabel prediktor terdiri dari pemupukan dan curah hujan tahun 2008 hingga 2018. Sedangkan variabel responnya adalah rendemen dari tahun 2008 hingga 2018. Sebelum dilakukan penaksiran model regresi dilakukan dahulu analisa pasangan data menggunakan scatter plot, pasangan data yang tidak rasional atau outlier dikeluarkan.

\section{HASIL DAN PEMBAHASAN}

Penelitian yang berjudul Pengaruh Curah Hujan dan Pemupukan terhadap Rendemen Tebu di PG Asembagus Situbondo telah dilaksanakan dengan pengambilan data sekunder. Hasil analisa ini merupakan sumber data pengkajian sebagai upaya nyata untuk merevitalisasi pabrik gula yang ada di Indonesia khususnya di Jawa Timur. Hasil analisa dari pengujian korelasi dan regresi antara rendemen tanaman tebu, curah hujan, dan pemupukan sebagai berikut.

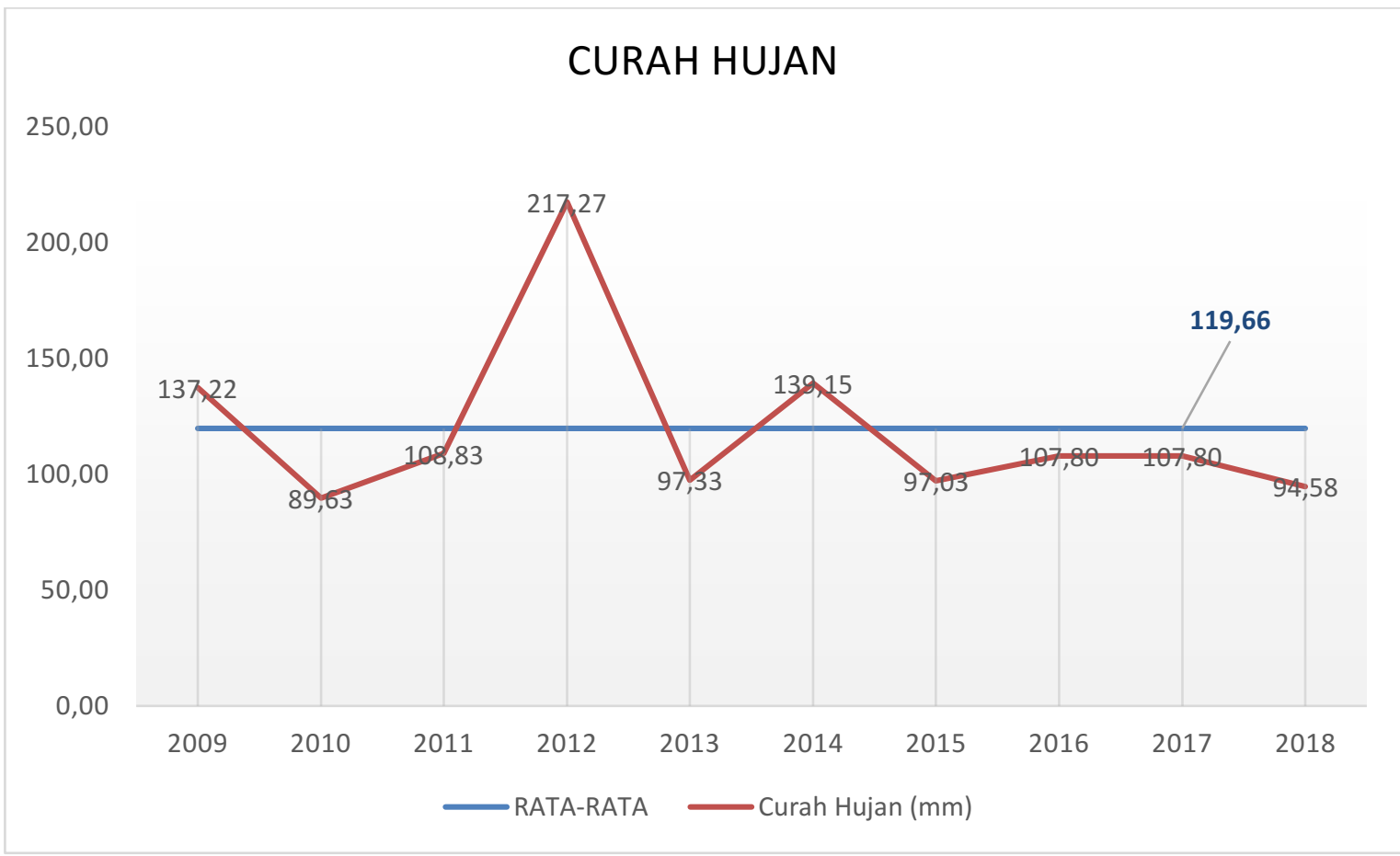

Gambar 1. Curah hujan tahun 2009-2018

Berdasarkan gambar 1 diketahui rata rata curah hujan dalam 10 tahun dari tahun 2009 sampai dengan tahun 2018 sebesar 119,66mm per tahunnya. Curah hujan di Asembagus dalam sepuluh tahun terakhir hamper selalu dibawah rata-rata. Curah 
hujan yang tertinggi terjadi pada tahun 2012 yakni sebesar 217,27 $\mathrm{mm} /$ tahun. Curah hujan rata-rata yang diperlukan adalah sekitar $1800-2500 \mathrm{~mm} /$ tahun. Jika curah hujan tidak cukup, maka harus diberi aliran air irigasi (Kuntohartono \& Thijsse, 2009). Pada kenyataannya karena minimnya curah hujan yang terjadi di daerah Asembagus maka pihak PG melakukan irigasi 2 sampai 3 kali selama masa tanam, terutama pada vase vegetative tanaman tebu. Untuk tanaman tebu fase kritis terletak pada saat pembentukan tunas dan pertumbuhan vegetatif yaitu pada saat umur 0-160 hari (Hanum, 2012).

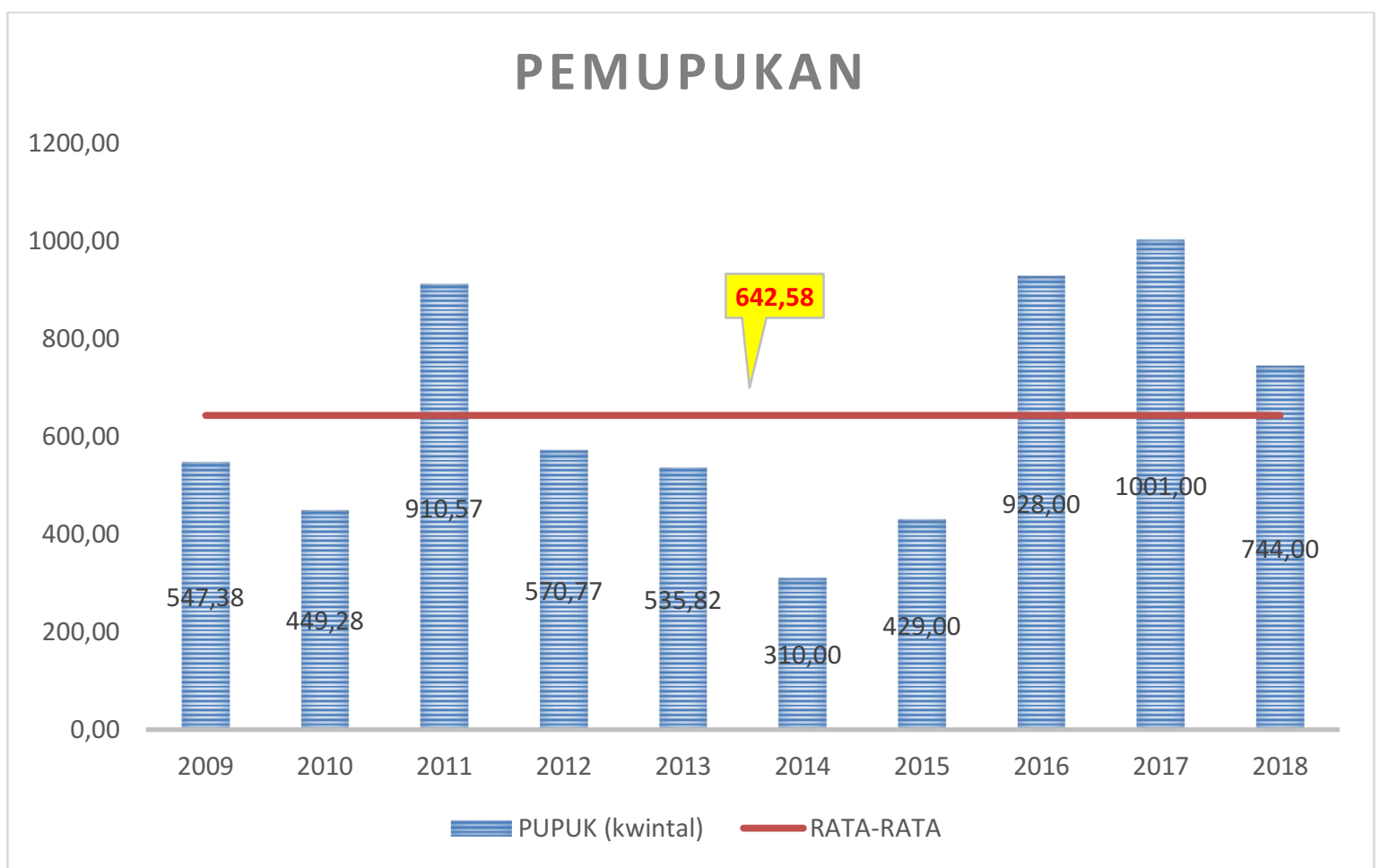

Gambar 2. Pemupukan tahun 2009-2018

Pupuk NPK yang diberikan pada tanaman tebu rata rata 642,58 kwintal per tahunnya dengan luas lahan rata-rata 543,79 hektar. Dosis pupuk yang diberikan selalu mengalami perubahan setiap tahunnya, menyesuaikan kondisi tanaman dan rekomendasi manajemen tanaman di PG Asembagus. Pemupukan yang dilakukan PG Asenbagus sebanyak 3 kali dengan pemupukan dasar, pemupukan kedua dan pemupukan ketiga, sesuai dengan pedoman pemupukan TRIT yaitu pupuk ZA dengan dosis 6-8 kw/ha, pupuk TSP dengan dosis 1-2 kw/ha dan pupuk KCL 1-2 kw/ha (Rukmana, 2015). Pemupukan yang dilakukan sesuai dengan umur tanaman. 


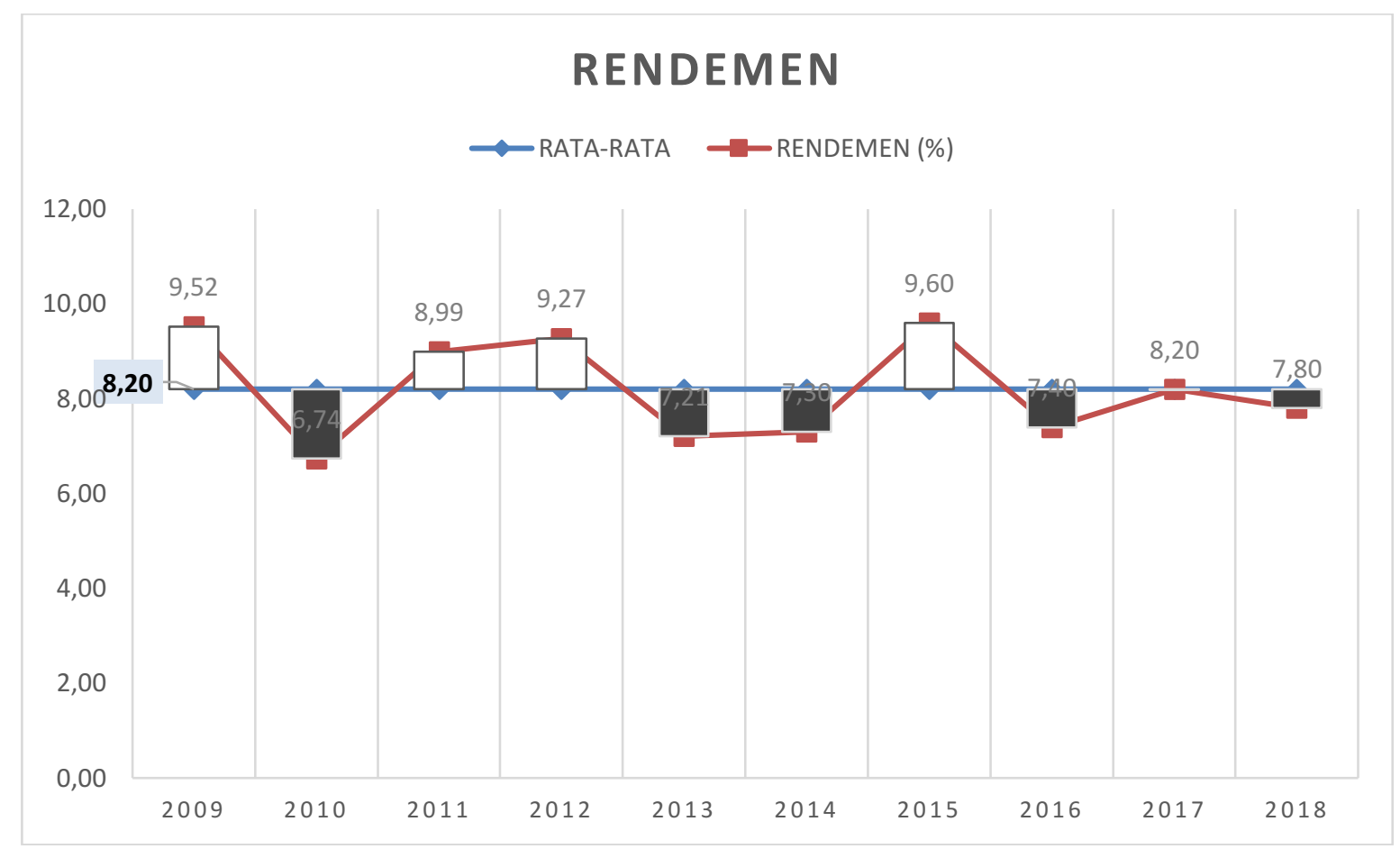

Gambar 3. Rendemen tahun 2009-2019

Berdasarkan gambar 3 terlihat ratarata rendemen yang dihasilkan dalam nira batang tebu 8,203\%. Rendemen merupakan kadar nira yang terkandung dalam batang tebu. Berdasarkan hal tersebut, rendemen adalah jumlah kilogram habrul/kristal gula yang terbentuk dari setiap kuintal tebu yang digiling (Supriadi,
1992) Misal nilai rendemen $8,2 \%$ artinya dihasilkan $8,2 \mathrm{~kg}$ gula dari $100 \mathrm{~kg}$ tebu. Berdasarkan data rendemen di PG Asembagus rendemen tertinggi mencapai 9,6\% pada tahun 2015 dan rendemen terendah sebesar $6,74 \%$ terjadi pada tahun 2010.

Tabel 1. Hasil Data Korelasi RendemenTanaman Tebu, Curah Hujan dan Pemupukan

\begin{tabular}{lll}
\hline & Rendemen (\%) & Curah_hujan (mm) \\
\hline Curah Hujan (mm) & 0,424 & \\
$P$-value & 0,222 & \\
Pemupukan (kw) & 0,056 & $-0,186$ \\
$P$-value & 0,877 & 0,608 \\
\hline
\end{tabular}

Berdassarkan tabel 1 hubungan/ korelasi antara rendemen tanaman tebu dan curah hujan sebesar 0,424, akan tetapi nilai $p$-value lebih dari 0,05. Hal ini menunjukkan hubungan yang lemah dan tidak signifikan antara curah hujan dengan rendemen tanaman tebu. Tetapi terlihat arah korelasinya adalah positif, hal ini menunjukkan hubungan searah antara rendemen tanaman tebu dengan curah hujan. Artinya ketika curah hujan tinggi, rendemen tanaman tebu turut meningkat, demikian sebaliknya.

Hubungan antara rendemen tanaman tebu dengan pemupukan sebesar 0,056 , dan nilai $p$-value juga lebih besar dari 0,05 . Hal ini menunjukkan hubungan yang sangat lemah dan tidak signifikan antara rendemen tananaman tebu dengan pemupukan, akan tetapi arah hubungan positif. Hal ini menunjukkan semakin 
banyak pemupukan maka semakin tinggi rendemen tanaman tebu yang dihasilkan. Kemudian hubungan antara curah hujan dan pemupukan sangat kecil/lemah, 0,087 dengan arah negatif atau berkebalikan dan tidak signifikan.

Tabel 2. ANOVA

\begin{tabular}{lcllll}
\hline Model & Sum of Squares & df & Mean Square & F & Sig. \\
\hline Regression & 4,194 & 2 & 2,097 & 7,53 & 0.031 \\
Residual & 1,392 & 7 & 0,2784 & & \\
Total & 5,586 & 9 & & & \\
\hline
\end{tabular}

Berdasarkan analisa sidik ragam diketahui bahwa nilai F-hitung sebesar 7,53 sedangkan $F$ tabel dengan alpha $(\alpha)$ 0,05 dan derajat bebas $(1,9)$ adalah 5,117. Sehingga diketahui bahwa nilai $\mathrm{F}$ hitung lebih besar dari $\mathrm{F}$ tabel, maka disimpulkan model regresi sudah sesuai. Model regresi yang terbentuk telah sesuai dengan kenyataan yang digambarkan.

Tabel 3. Koefisien Regresi

\begin{tabular}{llllll}
\hline Model & B & Std.Error & t & Sig. & VIF \\
\hline Konstanta & 4,373 & 0,927 & 4,72 & 0.005 & \\
Curah_hujan & 0,0167 & 0,005 & 3,4 & 0.019 & 1.07 \\
Pemupukan & 0,0022 & 0,0008 & 2,66 & 0.045 & 1.07 \\
\hline
\end{tabular}

Berdasarkan Tabel 3 diketahui bahwa konstanta model regresi atau $\beta 0$ sebesar 4,737 dengan koefisien regresi untuk curah hujan 0,0167 dan pemupukan 0,0022 . Pengaruh kedua variabel yakni curah hujan dan pemupukan secara statistik signifikan terhadap rendemen.. Hal ini terbukti dari nilai Sig. atau $P$-value lebih kecil dari 0,05 . Persamaan regresi yang dapat terbentuk adalah

$y=4,373+0,0167 X 1+0,0022 X 2$

Arti persamaan tersebut adalah jika X1 (curah hujan) dan pemupukan (X1) konstan, maka rendemen tebu sebesar $4,373 \%$, dan apabila curah hujan naik 1 $\mathrm{mm}$, kemudian pemupukan konstan maka rendemen tebu naik sebesar 0,0167\%. Demikian sebaliknya, jika curah hujan konstan dan pemupukan naik 1 kwintal, maka rendemen tebu naik sebesar $0,0022 \%$. Besarnya nilai koefisien determinasi yakni sebesar $75,08 \%$. Hal ini menunjukkan bahwa pengaruh curah hujan dan pemupukan terhadap rendemen tebu hanya sebesar $75,08 \%$, sedangkan $24,92 \%$ dipengaruhi oleh faktor lain. Seperti faktor iklim lainnya ketinggian tempat, kelembapan, suhu, kecepatan angin, dan faktor tanah seperti sifat fisik tanah dan kimia tanah (Evizal, 2018; Pramuhadi, 2016).

Curah hujan berpengaruh penting terhadap pertumbuhan tebu, pemasakan tebu, serangan hama penyakit terkait kelembaban udara, dan produktivitas gula terkait dengan kelancaran dan ketepatan operasional panen dan angkut. Sebaiknya curah hujan 1500-3000 mm/tahun dan menyebar merata diperiode pertumbuhan tebu agar produktivitas gula tinggi, dan pupuk yang diaplikasikan dapat terurai tersedia bagi tanaman tebu. Penyebaran hujan lebih penting daripada jumlah curah hujan. Pertumbuhan vegetatif diperlukan curah hujan yang tinggi (200 $\mathrm{ml}$ perbulan) selama 5-6 bulan (bulan basah) dan 3-5 bulan dengan curah hujan kurang dari 75 mm per bulan (bulan kering) periode ini 
merupakan pertumbuhan generatif dan pemasakan tebu, yang akan berpengaruh pada rendemen tebu. Dipertegas dengan pendapatnya Hartanto \& Barus (2018) bahwa tanaman tebu membutuhkan banyak air pada masa pertumbuhan tanaman atau masa vegetatif yang berperan untuk meningkatkan bobot batang tebu yang meliputi diameter batang dan tinggi batang.

Kecilnya pengaruh pemupukan pada PG. Asembagus kemungkinan besar disebabkan jenis tanah yang ada di Asembagus. Jenis tanah di Asembagus sesuai sumber dari PG Asembagus adalah tanahnya berpasir, dan tergolong jenis tanah regosol. Jenis tanah regosol memang mencirikan berpasir dimana porositas tanah cukup tinggi dan akan menyebabkan losses unsur hara. Hal ini yang menyebabkan baik pupuk ataupun air tersedia oleh tanaman tidak dapat berfungsi secara maksimal pada pertumbuhan tanaman tebu. Kandungan air dalam tanah merupakan faktor yang mempengaruhi pertumbuhan tanaman, dimana fungsi air yang utama adalah untuk proses metabolisme dan fotosintesis pada tanaman. Menurut Hartanto \& Barus (2018) tanaman tebu membutuhkan banyak air pada masa pertumbuhan tanaman atau masa vegetatif yang berperan untuk meningkatkan bobot batang tebu yang meliputi diameter batang dan tinggi batang. Oleh karena itu pengaturan air pada budidaya tanaman tebu harus dipenuhi sesuai dengan kebutuhan tanaman sehingga nantinya akan meningkatkan hasil produksi tebu. Pemupukan di PG. Asembagus dosis pupuk yang digunakan yaitu pupuk ZA $8 \mathrm{Ku} / \mathrm{Ha}$, SP36 1,5 Ku/Ha, dan $\mathrm{KCl} 2,5 \mathrm{Ku} / \mathrm{Ha}$.

\section{KESIMPULAN}

Berdasarkan hasil penelitian dan analisis data dapat disimpulkan bahwa curah hujan dan pemupukan secara simultan atau bersamaan berpengaruh signifikan terhadap rendemen tebu di PG. Asembagus dengan persamaan regresinya adalah:

$$
\begin{array}{r}
y=4,373+0,0167 \text { Curah Hujan } \\
+0,0022 \text { Pemupukan }
\end{array}
$$

dengan kontribusi curah hujan dan pemupukan sebanyak $75,08 \%$ berpengaruh terhadap rendemen tebu di PG. Asembagus dan sisanya sebesar $24,92 \%$ berasal dari pengaruh variabel lain yang tidak dimasukkan ke dalam model regresi.

\section{DAFTAR PUSTAKA}

Estiningtyas, W., Surmaini, E., \& Hariyanti, K. S. (2008). Penyusunan Skenario Masa Tanam Berdasarkan Prakiraan Curah Hujan di Sentra Produksi Pangan. Jurnal Meteorologi Dan Geofisika, 9(1).

Evizal, R. (2018). Pengelolaan Perkebunan Tebu. Graha Ilmu.

Hanum, C. (2012). Ekologi Tanaman. USUpress.

Harlianingtyas, I., Hartatie, D., \& Salim, A. (2018). Modeling of rainfall and fertilization factor of sugarcane productivity in Asembagus sugar factory Situbondo. $E \& E S, 207(1)$, 12013.

Hartanto, S., \& Barus, A. (2018). Tanggap Pertumbuhan Bibit Tebu Merah (Saccharum officinarum L.) Asal Bud Set terhadap Pemangkasan dan Frekuensi Penyiraman. Jurnal Pertanian Tropik, 5(1), 136-146.

Kuntohartono, T., \& Thijsse, J. P. (2009). Detil Data Saccharum officinarum Linn.

Pramuhadi, G. (2016). Faktor Iklim Pada Budidaya Tebu Lahan Kering. 
JURNAL PANGAN, 19(4), 331-344.

Rosdianingsih, D. (2013). Budidaya Tebu (Saccharum officinarum L.) Lahan Kering di PG. Madukismo PT. Madubaru Yogyakarta dengan Aspek Khusus Pemupukan Beberapa Kategori Tanaman Tebu Lahan Kering. Institut Pertanian Bogor.

Rukmana, H. R. (2015). Untung Selangit dari Agribisnis Tebu. Lilypublisher. Yogyakarta.

Sugiyono. (2017). Statistika Untuk Penelitian. Alfabeta.

Supriadi. (1992). Rendemen Tebu: Likuliku Permasalahannya. Kanisius. 